\title{
Innovation Design and Empirical Research Based on Prevention of Lumbar Muscle Strain and Sanitation Products
}

\author{
Ran Chen ${ }^{1}$, Ming Chen ${ }^{1,2}$ and Jian-hua Lyu ${ }^{1,2, a}$ \\ ${ }^{1}$ Forestry College, Sichuan Agricultural University, Chengdu 611130, China \\ ${ }^{2}$ Key Laboratory of Wood Industry and Furniture Engineering, Sichuan Agricultural University, Chengdu 611130, \\ China
}

\begin{abstract}
This article takes the lumbar muscles of degeneration status of Chinese sanitation workers as the starting point, analyzed the waist health status of sanitation workers in China. The design conception of sanitation products for the lumbar muscles of degeneration of sanitation workers was obtained by analysis, and the design of today's sanitation products are rethought, use relevant research results to demonstrate that. With sanitation products as the design center, it integrates many research contents such as ergonomics, appearance, function, process and cost. To this article has designed tools that sanitation workers can use to protect their waists while working, It also provides a new idea for the wide design of sanitation products. It is conducive to maintaining the basic rights and interests of sanitation workers and promoting the urbanization process and the harmonious development of society.
\end{abstract}

\section{INTRODUCTION}

Urban sanitation workers are very typical vulnerable groups in modern society, They are the main force of developing the urban environmental sanitation, and they have made a great contribution to the civilization, harmony and sustainable development of cities. More than 1000 employees mainly middle-aged and elder people are in sanitation related industries in China. According to incomplete statistics, sanitation workers aged 30-40 account for about $36 \%, 42 \%$ of $40-50$ years old, the percentage of people over the age of 50 is $24 \%$. Sanitation workers are mostly women, accounting for $74 \%$ of the total, and male workers only account for $26 \%$. Under the condition of long-term fatigue, the lumbar muscles of the middle-aged and elder people are prone to strain. Globally, especially in developing countries, perennially for sanitation workers use the sanitation products which are lacking of humanized design and less maneuverable, which causes that sanitation workers are generally in poor health, one of the most prominent is that the sanitation workers often use the waist as a support point in their working time. Therefore, a in-depth analysis of the health and working situation of sanitation workers in our country and propose corresponding solutions, to help protect the basic rights and interests of environmental sanitation workers, meantime, it is more conducive to urbanization and harmonious social development[1].

\section{ANALYSIS OF THE PRESENT SITUATION OF SANITATION PRODUCTS}

\footnotetext{
a E-mail: 1jh@sicau.edu.cn
} 


\subsection{Definition of sanitation products}

"Sanitation product" refers to a kind of product which is helpful to keep the environmental hygiene when it is necessary to clean the work to a certain extent, It can reduce the workload of people's cleaning, and can achieve a thorough cleaning effect through some special functions. Sanitation products are the equipment with heavily companionship with sanitation workers, after all the sanitation products affect the worker's health. More than $90 \%$ of sanitation operations need to be completed directly or indirectly through sanitation products, unscientific sanitation product design still is one of the causes of human health damage. Therefore, the design of good sanitation products can greatly reduce the damage of operation to human lumbar muscles.

\subsection{Analysis of the status of sanitation workers' health}

To investigate the health status of sanitation workers, and aurvey results show. Of the 429 sanitation workers inspected, only 32 were completely normal, $7.46 \%$ of the total number of persons examined.397 people were found to have abnormal indicators and suffer from various diseases(There is at least one index anomaly),92.54\% of the total number of persons examined[2]. At the same time, many sanitation workers have expressed a desire to obtain sanitation products that can reduce physical damage. The sanitation products for lumbar muscle strain have played a greater role in protecting the waist of workers. When cleaning the work at ordinary times, they can carry out the work more conveniently and quickly, reduce working hours and workload. The design of such products gives the mission and vitality of new environmental sanitation products to make sanitation workers less injurious to the body while working, and avoid mechanical injury such as lumbar muscle strain.

\subsection{Status Analysis of Environmental Sanitation Product Function}

With the rapid development of economic development and urbanization, the quantity of urban waste generated is also increasing year by year. The role of urban sanitation facilities in the process of urban modernization is particularly prominent[3]. The design of sanitation products has become an important part of sanitation engineering. At the current stage, China's environmental sanitation products are at a low level of mechanicality, intelligence, and portability. As far as the current situation is concerned, this type of domestic intelligent sanitation products is almost in a blank period. Therefore, the use of ergonomic scientific research methods to improve the design of sanitation products to improve the efficiency of sanitation workers to ensure the quality of life of sanitation workers and promote the harmonious development of the city[4].And effectively strengthen our attention to the construction of sanitation facilities.

\section{THE SANITATION PRODUCTS DESIGN PRINCIPLES AND PROOFS FOR AVOIDING LUMBAR MUSCLE STRAIN}

\subsection{Design process, systems, structure}

The design is center on environmental sanitation products and incorporates research contents such as appearance, function, process and cost(Figure 1). The appearance is mainly designed for color and shape to enhance recognition degree. In terms of the function, it mainly considers the operational requirements such as cleaning and portability. As for the process, it mainly aim at the design of structure and processing, and the utilization ratio of reinforced materials. In the cost, mainly considers the raw materials and production processes to enhance product cost performance. 


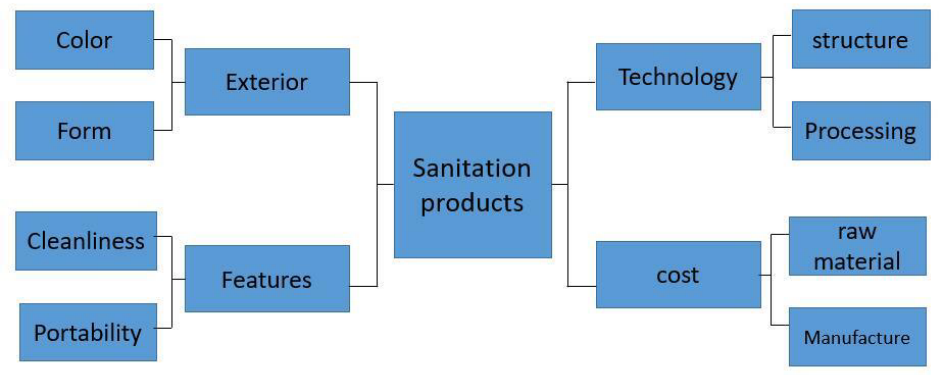

Figure 1.Product function design process, systems, structure diagram

\subsection{Design Principles}

When sanitation workers work, they often bend over and repeat this mechanical movements. After a period of time, the body parts, such as the waist, can be easily damaged. At the same time, because of the large amount of labor of the sanitation workers and poor product functionality, the design of the structure, selection of materials, and design of functions should be considered in the design of environmental sanitation products for avoiding lumbar muscle strain. Besides, in addition to sanitation products used by sanitation workers, some functional sanitation products for home use should also be designed. Therefore, besides considering the functionality in design, it should also combine the problems of portability, use of space, and user crowds, after that the design of sanitation products can solve problems and meet people's daily needs.

\subsubsection{Principle of structural stability}

Structure refers to the composition and combination of the elements of a product or object. Structural design is an important part of product design[5]. In the product design, the structure of the product is a necessary condition for achieving the function of the product, and it will directly affect the structural characteristics and appearance of the product. So when design a sanitation product, it is necessary not only to ensure the safety of sanitation workers during operations, but also to avoid mechanical repetitive actions to the greatest extent possible. Make full use of mechanical principles and rationally construct the structural system so that it can be stable and safe.

\subsubsection{Material Selection Principles}

Tool material is the material basis for product function and it is also the carrier of product design. The material properties and material types of product materials not only affect the appearance of product design, but also have functional restrictions. Functional sanitation products should be portable and easy to be cleaned during operation. Therefore, in the selection of materials, it is necessary to satisfy the variability in structure through the deformation of the material to achieve the desired function. At the same time, the pros and cons of materials can also affect the service life circle and clean-ability. So in the selection of materials, it is necessary to choose a material that is easy to clean on the surface.

\subsubsection{Principle of Cleanliness}

Sanitation products refer to the products that perform clean operations on facilities. Not only are they required to be able to clean the dirt, but they also need to ensure that the products themselves do not become moldy, smelly or contaminated. During the sanitation working period, where pollution is heavy and air circulation is poor for a long period of time, in order to improve its operating efficiency and satisfaction with work, the first condition is to ensure that it uses clean products and is in a clean environment. Therefore, in the process of product design, in addition to the choice of cleanable 
materials, it is also possible to use vents, activated carbon and other components, and clean itself to meet the requirements of cleaning products that can clean themselves.

\subsubsection{Functional Diversity Principle}

In recent years, more and more equipments are needed for cleaning. Due to the lag in product design, many sanitation workers are still using traditional sanitation products, which have a single function and are inconvenient to carry. Therefore, we have added new features such as portability and intelligent technology in product design, so that sanitation workers can play a role in new functional environmental sanitation products during operations, which can improve the practical value of sanitation products, and adapt to the design principles of social development.

\subsection{Design evidence}

According to the innovative design ideas and approaches discussed in the study, the design verification was carried out. Three design proposals were obtained and utility model patents were declared.

\subsubsection{Sanitation tools designed to clean the surface of cylindrical structures}

A sanitation tool dedicated to cleaning the surface of cylindrical structures (Figure 2), The rod body is provided with an ultrasonic generator and an ultrasonic transmission cover, the ultrasonic generator is connected with the ultrasonic transmission cover, and the ultrasonic transmission cover is communicated with the open end of the rod body, and the ultrasonic generator is arranged under the sealing plug. The ultrasonic transmission cover is disposed between the ultrasonic generator and the sealing plug. With the principle of clamping mechanism, after deformation, the object to be cleaned is squeezed by force, and the cavitation effect of ultrasonic waves occurs. The ultrasonic wave is transmitted to clean liquid with high frequency transformation mode of alternating force and pressure reduction more than 20,000 times per second. When the pressure is reduced, the phenomenon of vacuum nuclear group bubbles is generated. When the compressible force is applied, the vacuum nuclear group bubble produces a strong impact force when crushed by pressure. This removes the dirt on the surface of the object to be cleaned, thereby achieving the purpose of precise washing. The structure of the tool is simple, the operator can directly contact with the isolation fence without bending, the single contact area is large, and the wiping efficiency is improved.

\subsubsection{Equipment for deodorization and effusion elimination based on garbage.}

Based on equipment for deodorization and liquid elimination of waste (Figure 3). The top surface of the base is recessed to form a groove, a mounting platform is installed in the groove, a through hole is arranged on the mounting platform, a collecting barrel is arranged in the through hole, and a filter mesh is arranged in the collecting barrel. An exhaust pipe is arranged on the installation platform, an adsorption tank is connected to the bottom of the exhaust pipe, an adsorption layer is arranged in the adsorption tank, and an intake pipe is arranged on the sidewall of the adsorption tank. A suction pump is provided on the installation table, and the suction pump is connected to the intake pipe. One end of the air inlet tube is communicated with the inside of the adsorption tank, and the communication between the air inlet tube and the adsorption tank is located below the adsorption layer. The other end of the air inlet tube is provided with an adsorption hood, and a concentration detector is arranged in the adsorption hood. The side wall of the base is con-caved to form a treatment chamber, a liquid collection tray is disposed in the treatment chamber, and a heating plate is disposed in the treatment chamber. The device can timely process the liquid produced in the garbage can, prevent the liquid from accumulating and damaging the trash can, and also prevent the odor from being emitted into the air. The device reduced the sanitation workers' cleaning process against the trash and greatly reduced 
the workload of sanitation workers.

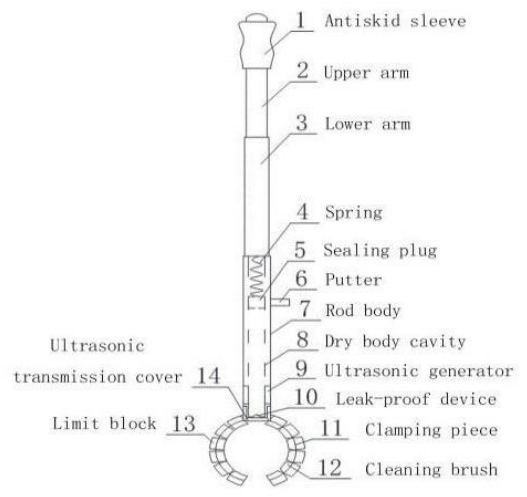

Figure 2.A sanitation tool that can be exclusively used deodorization in cleaning the surface of cylindrcal structure

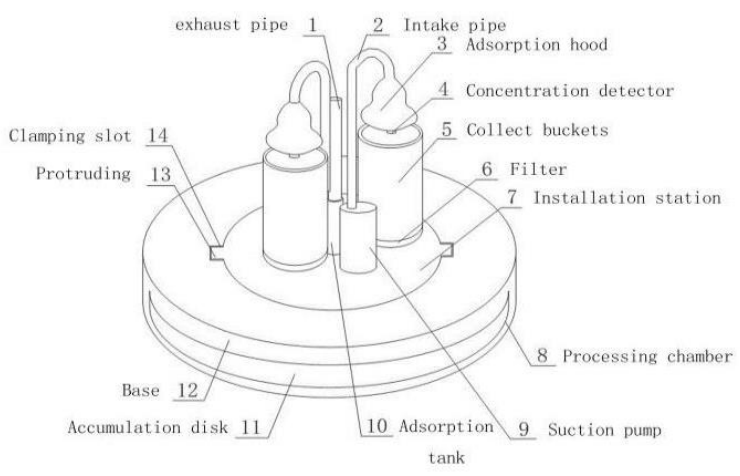

Figure 3. The equipment is based on and effusion of waste

\subsection{3 multifunctional sanitation cleaning tool cart}

A multifunctional sanitation cleaning tool vehicle (Figure 4). The bottom of the vehicle body is provided with wheels, a garbage adsorber is installed on the body, a garbage collection bin is arranged in the vehicle body, and a barrier net is arranged in the garbage collection bin. A suction pump is provided in the vehicle body, and the suction pump is connected to a garbage adsorber. A solar panel is arranged on the vehicle body, a steering rod is arranged on the vehicle body, a steering rod is provided with an operating rod, an operating button is arranged on the operating rod, an insertion umbrella frame is fitted on the steering rod, and an umbrella stand is arranged on the insertion umbrella An umbrella hole is inserted, a battery box is arranged on the vehicle body, an extension frame is arranged at the tail part of the vehicle body, and a hinge is arranged between the extension frame and the tail part of the vehicle body. A seat cushion is arranged on the top of the vehicle body, a fan is arranged on the side wall of the vehicle body, and an air outlet is arranged at the top of the vehicle body near the seat cushion. The utility model has the advantages of simple structure, capable of automatically picking up the small garbage, avoiding the bending work of the sanitation workers, reducing the labor intensity and the lumbar muscle strain rate of the sanitation workers, improving the picking efficiency, and improving the degree of cleaning, and achieved versatility
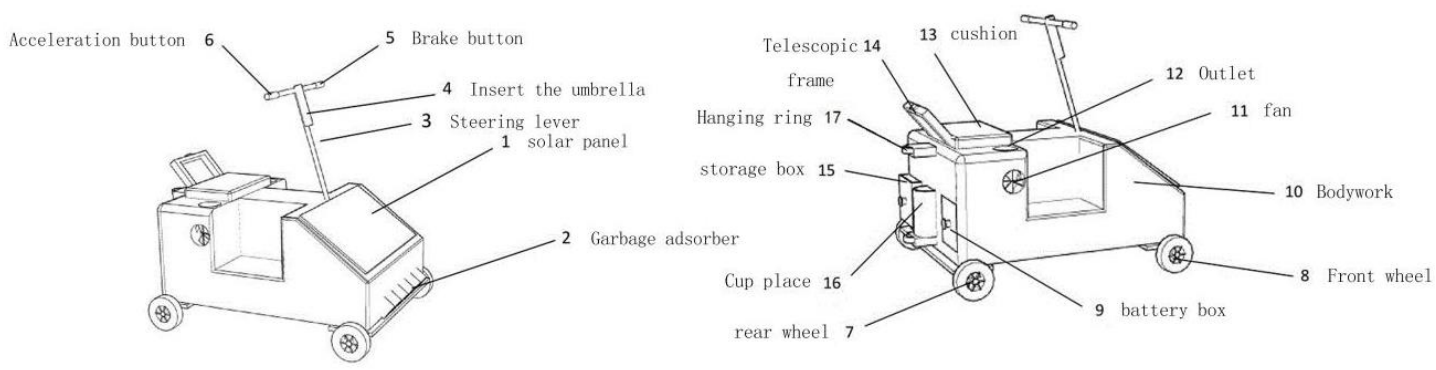

Figure 4. A multi-funcion sanitation vehicle

\section{SANITATION PRODUCT DESIGN EVALUATION}

The construction of the sanitation product index system will follow the design principles and will proceed from the three dimensions of function, technology and economy, and it also combine other dimensions to establish an evaluation structure for sanitation products. The selection of sanitation 
products for prevention of lumbar muscle strain must consider the three dimensions of the general evaluation criteria, and at the same time, it should also pay attention to selecting the appropriate evaluation angle, and establish multi-rate evaluations from users to production companies to society, from multiple perspectives of vision, touch, psychology, practicality, protection, function, material, craftsmanship, and cost, benefit, a multi-level comprehensive evaluation system (table 1).

Table 1.Multi-dimensional product evaluation

\begin{tabular}{|c|c|c|}
\hline $\begin{array}{c}\text { Evaluation } \\
\text { Dimension }\end{array}$ & Evaluation method & effect \\
\hline Features & $\begin{array}{c}\text { Qualitative and } \\
\text { quantitative }\end{array}$ & $\begin{array}{c}\text { Calculate user needs and product operability and } \\
\text { satisfaction for product function optimization } \\
\text { evaluation }\end{array}$ \\
\hline technology & $\begin{array}{c}\text { Qualitative and } \\
\text { quantitative }\end{array}$ & $\begin{array}{c}\text { Analyze product structure, process, etc., priorities of } \\
\text { select technical }\end{array}$ \\
\hline economic & Quantitative evaluation & $\begin{array}{c}\text { Evaluation of product estimates through product } \\
\text { cost estimates and sales statistics }\end{array}$ \\
\hline
\end{tabular}

\section{CONCLUSION}

At present, the demand for products of sanitation workers is not satisfied with the sanitation product when they are working, the needs have already evolved to the stage where higher quality and more convenient products are required. On the one hand, the increase in the number of manufacturers of environmental sanitation machinery has made the manufacturers compete with each other more and more fierce. On the other hand, the market segmentation has become more sophisticated, and a number of more specialized sanitation machinery companies have emerged[6]. The design of environmental sanitation machinery products can guide the design completion with innovative methods.

Through the idea of strategic innovation, reasonable use of different innovative methods to guide product design. When determining the overall plan, through the innovative method of FBS function mapping, starting from the main function of the product, using the scientific effect library to find a number of appropriate principles and programs, and then the optimal program is selected [7]. There are many areas involved in sanitation products. Besides the product design theory itself, it also has a great deal of connection with the fields of dynamics, mechanical engineering, and electronic engineering. With the progress of the society, environmental sanitation has become more and more demanding for intelligent products. To meet the demand for multi-purpose use of sanitation workers, it is necessary to recreate and redesign existing sanitation products at the current stage. Relative research and application are still lagging behind. There is still a great deal of room for research and development in the theoretical foundation, implementation approaches, and technical means.

\section{ACKNOWLEDGMENTS}

This research is supported by Research Project of Double Support Program for Art Special Project in Sichuan Agricultural University(2018). This research was carried out at the Sichuan Provincial Colleges and Universities Wood Industry and Furniture Engineering Key Laboratory, Sichuan Agricultural University. 


\section{References}

1. Liu Hongsheng, Yan Yifan. Research on the Safeguarding of the Operation of Urban Sanitation Workers[J]. Journal of Shaanxi Administration Institute, 2007, 11:21-4.

2. Xiong Chengbiao, Xue Genshan. Health check-ups and health-related factors in Haikou sanitation workers[J]. China Tropical Medicine, 2013,13(8)994-996

3. Gao Chunmei. Research on the practicality of "3R" principle in product design of urban sanitation facilities [D]. Nanchang, Nanchang University, 2012.

4. Bai Rui, Xue Yanmin, Qin Song. Innovative Design of Environmental Sanitation Products Based on Survey[J]. Art and Design, 2010(4):213-215.

5. Sun Delin, Sun Debin. Discussion on the Teaching Mode of "Furniture Structure Design"[J]. Journal of Central South Forestry Science and Technology, 2009(6):127-129.

6. Lin Qi. Research on Sanitation Machinery Industry[D]. Wuhan, Central China Normal University, 2015.

7. Chen Lin, Zhao Wu. Design of Environmental Sanitation Machinery Based on Innovative Methods[J]. Mechanical Design \& Manufacture, 2010(12):253-254. 